\title{
The Medi-RIVAGE study (Mediterranean Diet, Cardiovascular Risks and Gene Polymorphisms): rationale, recruitment, design, dietary intervention and baseline characteristics of participants
}

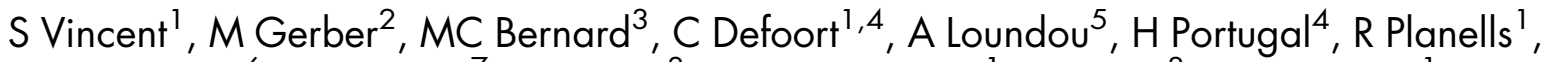 \\ I Juhan-Vague ${ }^{6}$, P Charpiot ${ }^{7}$, P Grolier ${ }^{8}$, W Amiot-Carlin ${ }^{1}$, P Vague ${ }^{3}$ and D Lairon ${ }^{1, *}$ \\ 'Unit 476 - Human Nutrition and Lipids at INSERM (National Institute of Health and Medical Research), Faculty of \\ Medicine Timone, Méditerranée University, 27 boulevard Jean Moulin, F-13385 Marseille Cedex 5, France: \\ ${ }^{2}$ Cancer Research Centre, INSERM-CRLC (Cancer Research Centre) Val d'Aurelle, Montpellier, France: ${ }^{3}$ CDPA \\ (Centre for Detection and Prevention of Arteriosclerosis), Timone University Hospital, Marseille, France: ${ }^{4}$ Analytical \\ Chemistry Laboratory, Faculty of Pharmacy, Marseille, France: ${ }^{5}$ ORS (Health Regional Observatory) Provence-Alpes- \\ Côte d'Azur, Marseille, France: ${ }^{6}$ Haematology Laboratory, INSERM EPI 99-36, Timone University Hospital, \\ Marseille, France: ${ }^{7}$ Biochemistry Laboratory, Faculty of Pharmacy, Marseille, France: ${ }^{8}$ UMMM (Metabolic Disease \\ and Micronutrients Unit) Laboratory, Vitamin Group at INRA (National Institute of Agronomic Research), \\ Clermont-Ferrand, France
}

Submitted 17 March 2003: Accepted 1 October 2003

\begin{abstract}
Objective: To report the rationale, recruitment, design, dietary intervention and baseline characteristics of participants in the Medi-RIVAGE study (Mediterranean Diet, Cardiovascular Risks and Gene Polymorphisms).

Design: A randomised, parallel trial comparing a new nutritional programme with a conventional programme.

Setting: Centre for Detection and Prevention of Arteriosclerosis, Timone University Hospital, Marseille, France, and collaborating teams.

Subjects: Two hundred and twelve male and female volunteers with at least one cardiovascular risk factor.

Intervention: A Mediterranean-type diet characterised mainly by the quality of fatty acids, amount of fish, vegetable foodstuffs and fibre was proposed and compared with a usually prescribed, low-fat/cholesterol diet. Body mass index, fasting lipids and lipoproteins, apolipoproteins, glucose, insulin and homocysteine were the main outcome measures. Gene polymorphisms of interest were determined.

Results: Characteristics of men in the two arms were comparable with regard to sociodemographic variables, and clinical and biological cardiovascular risk factors. There were few differences between the groups of women (cholesterol-related parameters, $P<0.05$ ). There was no difference between arms in allelic distribution of the gene polymorphisms studied. Saturated fat and protein intakes were high while carbohydrate and fibre intakes were low, but with no difference between arms. Overall, the nutritional markers were comparable in both arms with few exceptions. Correlations between nutritional intakes and plasma nutrient levels ranged from 0.19 ( $\beta$-carotene) to 0.47 (folate).

Conclusions: The comparability of the two arms is notable and warrants a low risk of biases. Current diet departs from the traditional Mediterranean one. The assessment of nutritional intake is validated by correlations obtained between dietary intake and relevant biomarkers. This will be important to estimate participant compliance and to analyse intervention data.
\end{abstract}

Keywords Lipid metabolism Intervention trial Primary prevention Micronutrients Metabolic syndrome
Cardiovascular diseases (CVD) are the leading causes of death in the Western world, accounting for almost 50\% of deaths in Europe and North America. They are also the third leading cause of mortality in developing countries, amounting to about $25 \%$ of all deaths ${ }^{1}$. Plausible projections of future mortality and disability indicate that ischaemic heart disease will remain the leading cause of death at least up to $2020^{2}$.

The relationship between CVD and food habits is well documented. In the Seven Countries Study initiated by 
Keys in the 1960s, a link between saturated fat intake, fasting blood cholesterol level and coronary disease mortality was shown among different populations ${ }^{3,4}$. In the 25-year follow-up 5 , important differences remained between countries with different food habits and a strong association between blood cholesterol level and coronary disease mortality was found. The recent Nurses' Health Study and Health Professionals' Follow-up Study by Willett's group confirmed the major role of dietary pattern in the prevention of coronary heart disease (CHD $)^{6}$.

The Seven Countries Study ${ }^{3-5}$ was the first to emphasise the potential benefits of a Mediterranean diet in the prevention of CVD. The results of this seminal study, which was based on food disappearance sheets and mortality data, have been confirmed by the more recent European MONICA (Monitoring Trends and Determinants in Cardiovascular Disease) project based on actual nutritional intake and CHD incidence ${ }^{7}$. The effect of some Mediterranean food items has been reported and reviewed by Kushi et al. ${ }^{8}$, Trichopoulou et al. ${ }^{9}$ and Gerber et $a l .{ }^{10}$. However, important changes in the food habits of Mediterranean populations have occurred and the Mediterranean model now appears to be restricted to older people and rural areas, with urbanised young people departing from it ${ }^{11}$. In a review, Ferro-Luzzi et al. ${ }^{12}$ claimed that, even in Crete, there is a progressive upward trend in total and saturated fat intakes concomitant with a remarkable increase in obesity and cardiovascular mortality.

It is generally accepted that intervention studies are the best method to validate a hypothesis suggested by ecological and/or analytical epidemiological studies. However, most intervention studies have been based on antioxidant supplementation given their expected role in CVD protection ${ }^{13-16}$. Results have been disappointing, leading to the development of a holistic concept of diet as opposed to isolated nutrients. Hence, instead of supplementation-based intervention studies, food pattern intervention studies have to be implemented. Indeed, Traeden et al. ${ }^{17}$ demonstrated the effectiveness of a dietary intervention strategy on cholesterol concentration in hypercholesterolaemic patients.

The first goal of the Medi-RIVAGE study (Mediterranean Diet, Cardiovascular Risks and Gene Polymorphisms) was primary prevention of CVD by evaluating the effect of a Mediterranean diet, as compared with a low-fat diet, on arteriosclerosis risk factors in subjects presenting at least one risk factor. The study is being conducted in southern France, where French Mediterranean populations have been found to be giving up their original dietary habits ${ }^{11}$. A second objective of the study was to implement extensive biological investigations in relation to the dietary intervention, with a special interest in post-prandial examination of lipid and lipoprotein parameters, as well as some genetic polymorphisms influencing lipoprotein metabolism and homeostasis.
In this first report, we describe the rationale, recruitment, design, dietary intervention and baseline characteristics of the participants.

\section{Methods}

\section{Subjects}

Participants were volunteers visiting the Centre for Detection and Prevention of Arteriosclerosis (CDPA) at Timone University Hospital in Marseille, France, who presented at least one of the eligibility criteria listed in Table 1. For lipid parameters, glycaemia and blood pressure, an upper limit was fixed to exclude treated subjects. Eligible volunteers signed informed consent as approved by the institution's ethics committee. A schedule, generated by computer using a random number generator, was used to assign participants to one of two diets.

A sample size of 80 subjects in each arm was calculated to have $90 \%$ statistical power to detect a difference of $0.5 \mathrm{mM}$ in blood cholesterol level with a $5 \%$ level of significance (two-tailed test).

\section{Study design}

The trial consists of a comparison of the efficacy of two dietary interventions: a Mediterranean-type diet and a lowfat diet as usually prescribed by the American Heart Association (AHA). Detailed descriptions of the energy and nutrients in each diet are given in Table 2, and food items are described below. The endpoints were observed changes in the risk factor(s) and biological markers, after 3 and 12 months of dietary intervention. A DNA bank was also built up to allow determination of gene polymorphisms involved in lipoprotein metabolism and/or arteriosclerosis and to search for interaction(s) between gene polymorphisms and responses to diets.

\section{Dietary intervention strategy}

\section{MED arm}

Participants received a booklet presenting the recommended Mediterranean (MED) diet, adapted from

Table 1 Inclusion criteria of the Medi-RIVAGE study* (Mediterranean Diet, Cardiovascular Risks and Gene Polymorphisms)

\begin{tabular}{ll}
\hline Fasting cholesterol $\left(\mathrm{mmoll}^{-1}\right)$ & $6.5-7.7$ \\
Fasting triglycerides $\left(\mathrm{mmoll}^{-1}\right)$ & $2.1-4.6$ \\
Fasting glucose $\left(\mathrm{mmol} \mathrm{I}^{-1}\right)$ & $6.1-6.9$ \\
$\begin{array}{l}\text { Body mass index }\left(\mathrm{kg} \mathrm{m}^{-2}\right) \\
\text { Current smokers }\end{array}$ & $>27$ \\
& $\begin{array}{l}\text { At least } 5 \text { cigarettes a day for the } \\
\text { last year }\end{array}$ \\
& Sedentary at work \\
Sedentarianism & No leisure-time physical activity \\
Family history of & Yes (at least one direct parent) \\
cardiovascular diseases & Systolic blood pressure $(\mathrm{mmHg}):$ \\
Hypertension & $140-180$ \\
& Diastolic blood pressure $(\mathrm{mmHg}):$ \\
& $90-105$
\end{tabular}

*Eligible subjects were defined as having at least one of the criteria listed (established cardiovascular risk factors in adults) and no exclusion criteria (see text for details). 
Table 2 Daily nutritional profiles recommended in each intervention arm

\begin{tabular}{|c|c|c|}
\hline & CDPA/AHA diet & MED diet \\
\hline Carbohydrate & $\begin{array}{l}55-60 \% \text { of total energy intake, mainly } \\
\text { complex }\end{array}$ & $\begin{array}{l}50 \% \text { of total energy intake, mainly } \\
\text { complex }\end{array}$ \\
\hline Protein & $\begin{array}{l}15 \% \text { of total energy intake, ratio } \\
\text { of animal/vegetable protein }=1\end{array}$ & $12-15 \%$ of total energy intake \\
\hline Fat & $30 \%$ of total energy intake & $35-38 \%$ of total energy intake \\
\hline PUFA/SFA & $=1$ & $\geq 0.5$ \\
\hline MUFA/SFA & & $>1$ \\
\hline SFA & $8-10 \%$ of energy & $8-10 \%$ of energy \\
\hline PUFA & $10 \%$ of energy & $8-10 \%$ of energy \\
\hline MUFA & $10 \%$ of energy & $18-20 \%$ of energy \\
\hline Cholesterol & $<300 \mathrm{mg}$ & $\leq 300 \mathrm{mg}$ \\
\hline Fibre & $>20 \mathrm{~g}$ & $>25 \mathrm{~g}$ \\
\hline Vitamin C & $>100 \mathrm{mg}$ & $100 \mathrm{mg}$ \\
\hline Carotenoids & & $7 \mathrm{mg}$ \\
\hline Alcohol & $\begin{array}{l}\leq 4 \% \text { of total energy intake (women), } \\
\leq 7 \% \text { of total energy intake (men) }\end{array}$ & $\begin{array}{l}\leq 4 \% \text { of total energy intake (women), } \\
\leq 5 \% \text { of total energy intake (men) }\end{array}$ \\
\hline
\end{tabular}

CDPA - Centre for Detection and Prevention of Arteriosclerosis; AHA - American Heart Association; MED Mediterranean; PUFA - polyunsaturated fatty acids; SFA - saturated fatty acids; MUFA - monounsaturated fatty acids.

the traditional one to the present time. A variety of raw or cooked, fresh or dry fruit and vegetables should be eaten at least three times daily. It was advised to include seasonal products. Legumes, nuts and dry fruit were recommended once to twice a week. Fish was recommended four times a week, red meat only once. Poultry and an egg-based dish should make the other two main meals. Sheep and goat should provide the main source of animal products, meat and dairy food. Tomato sauce should be largely used for cooking, and olive oil should be the essential added lipid, with a part of canola oil. Butter was only accepted once a week for breakfast and should be replaced on other days by yoghurt or cottage cheese. Wholemeal bread and cereals were recommended. Two glasses of wine per day were accepted for men and one glass for women.

To facilitate compliance, a set of three menus for each day of 2 weeks in winter/spring and 2 weeks in summer/autumn were provided together with recipes. For each menu, the energy, macro- and micronutrient intakes were calculated and the means were computed over the week using IDI software ${ }^{18}$ based on the REGAL food database ${ }^{19}$. Considering the body mass index (BMI) and physical activity of the participant, dietitians selected appropriate food portions from a validated set of photographs ${ }^{20}$ with three different food portion sizes.

Participants were provided with tomato paste, olive oil and soluble fibre-enriched pasta. A list of commercial ready-to-use salads and dishes compatible with the study criteria was also given to the participants.

\section{CDPA/AHA arm}

Recommendations were given to the subjects and a dedicated booklet provided. A caloric restriction was advised when BMI was $>25 \mathrm{~kg} \mathrm{~m}^{-2}$, by specifying the size of the food portions. It was recommended to choose poultry over other animal meats, which should be limited to 120-150 g per day; offal should be avoided; fish (not preserved in oil) should be eaten two or three times a week; and eggs no more than two or three times weekly. Skimmed dairy products were recommended, as were vegetable oils, whereas added animal fats (butter, cream, lard, etc.) had to be consumed moderately; and low-fat cooking methods (steaming, non-stick pans, etc.) were strongly suggested. Consumption of raw and cooked fruit and vegetables was recommended; rice, pasta, bread, legumes and potatoes were allowed but sugar, honey, jam, chocolate and other sweets should be restricted; spices and herbs should be used to make tasty dishes. Alcohol was to be avoided.

\section{Baseline and follow-up protocols}

The protocols were identical for both arms. Table 3 displays the medical and biological examinations conducted, as well as the nutritional markers determined. On the first day of the study, usual sociodemographic data were collected, including questions on psychological scale and physical activity. Leisure and work physical activity were estimated as shown in Table 4 . A dietitian performed the dietary assessment using a 3-day recall questionnaire. In addition, two or three 24-hour recalls were obtained by phone call during the first 3-month period, without prior knowledge of the subjects. The GENI software (Micro6, Nancy, France), based on the French REGAL food database, was used for calculation of nutrient intakes. A more specific food composition table for total and soluble dietary fibre was also used.

The standardised test meal used for post-prandial examination comprised rusks (six), margarine (40g), sugar (10 g), jam (30 g) and coffee or tea ad libitum, to which 50000 UI of retinyl palmitate (Avibon; Theraplix, Montrouge, France) was added per meal. 
Table 3 Clinical and biological examinations conducted at inclusion and after 3 and 12 months

\begin{tabular}{|c|c|c|}
\hline & Fasting measurement & $2.5 \mathrm{~h}$ and $5 \mathrm{~h}$ after a test meal \\
\hline Medical examinations & $\begin{array}{l}\text { Intima-media thickness } \\
\text { Body mass index } \\
\text { Waist/hip ratio } \\
\text { Systolic arterial blood pressure } \\
\text { Diastolic arterial blood pressure }\end{array}$ & \\
\hline Biological markers & $\begin{array}{l}\text { Total cholesterol } \\
\text { High-density lipoprotein cholesterol } \\
\text { Low-density lipoprotein cholesterol } \\
\text { Triglycerides } \\
\text { Glucose } \\
\text { Insulin } \\
\text { Homocysteine* } \\
\text { Cholesterol, phospholipids, triglycerides } \\
\text { in triglyceride-rich lipoprotein fraction } \\
\text { Apolipoprotein A-I } \\
\text { Apolipoprotein B } \\
\text { Apolipoprotein B-48 } \\
\text { Apolipoprotein C-III } \\
\text { Apolipoprotein E } \\
\text { Plasminogen activator inhibitor-1 antigen } \\
\text { Tissue plasminogen activator antigen } \\
\text { Fibrinogen }\end{array}$ & $\begin{array}{l}\text { Triglycerides } \\
\text { Glucose } \\
\text { Insulin } \\
\text { Cholesterol, phospholipids, triglycerides in } \\
\text { triglyceride-rich lipoprotein fraction } \\
\text { Apolipoprotein B-48 }\end{array}$ \\
\hline Nutritional markers & $\begin{array}{l}\text { Plasma fatty acids* } \\
\text { Carotenoids }^{*} \\
\text { Phenolic compounds* } \\
\text { Folic acid } \dagger \\
\text { Vitamin } B_{12} \dagger\end{array}$ & etinvl palmitate \\
\hline Genetic polymorphisms & At inclusion & \\
\hline
\end{tabular}

*Analysis also repeated after 6 months.

† Analysis also repeated after 6 and 9 months.

Table 4 Socio-economic characteristics of the sample by treatment group at baseline. Values are expressed as $n(\%)$ or mean \pm standard deviation $(n=212)$

\begin{tabular}{|c|c|c|c|c|c|c|c|c|c|}
\hline & \multicolumn{3}{|c|}{ MED diet } & \multicolumn{3}{|c|}{ CDPA/AHA diet } & \multicolumn{3}{|c|}{$P$-value } \\
\hline & Total & Men & Women & Total & Men & Women & Total & Men & Women \\
\hline$n(\%)$ & $102(48.1)$ & $40(39.2)$ & $62(60.8)$ & $110(51.9)$ & $42(38.2)$ & $68(61.8)$ & & & \\
\hline Age (years) & $50.2 \pm 11.4$ & $48.4 \pm 12.2$ & $51.3 \pm 10.1$ & $51.5 \pm 9.9$ & $50.6 \pm 8.6$ & $52.0 \pm 10.7$ & 0.4 & 0.5 & 0.5 \\
\hline Activity & & & & & & & 0.3 & 0.3 & 0.2 \\
\hline Active & $69(67.6)$ & 27 (67.5) & $42(67.7)$ & $68(61.8)$ & $30(71.4)$ & $38(55.8)$ & & & \\
\hline Retired & $22(21.6)$ & $9(22.5)$ & $13(21.0)$ & $26(23.6)$ & $11(26.2)$ & $15(22.1)$ & & & \\
\hline Without occupation & $11(10.8)$ & $4(10.0)$ & 7 (11.3) & $1(14.5)$ & $1(2.4)$ & $15(22.1)$ & & & \\
\hline Occupational status & & & & & & & 0.7 & 0.9 & 0.08 \\
\hline Blue collar workers & 34 (33.3) & $12(30.0)$ & $22(35.5)$ & $38(34.5)$ & $13(31.0)$ & $25(36.8)$ & & & \\
\hline Office workers and executives & $12(11.8)$ & $6(15.0)$ & $6(9.7)$ & $10(9.1)$ & $8(19.0)$ & $2(2.9)$ & & & \\
\hline Employees or manual workers & $26(25.5)$ & $9(22.5)$ & 17 (27.4) & $21(19.1)$ & $10(23.8)$ & $11(16.2)$ & & & \\
\hline None & $30(29.4)$ & $13(32.5)$ & $17(27.4)$ & $41(37.3)$ & $11(26.2)$ & $30(44.1)$ & & & \\
\hline Marital status & & & & & & & 0.7 & 0.2 & 0.2 \\
\hline Yes & 77 (76.2) & 37 (92.5) & $40(65.6)$ & $86(78.2)$ & 35 (83.3) & $51(75.0)$ & & & \\
\hline No & $24(23.8)$ & $3(7.5)$ & $21(34.4)$ & $24(21.8)$ & 7 (16.7) & $17(25.0)$ & & & \\
\hline Work physical activity & & & & & & & 0.3 & 0.9 & 0.2 \\
\hline Sedentary & $56(54.9)$ & $23(57.5)$ & $33(53.2)$ & $69(62.7)$ & $25(59.5)$ & $44(64.7)$ & & & \\
\hline Light or medium & $46(45.1)$ & $17(42.5)$ & $29(46.8)$ & $41(37.3)$ & $17(40.5)$ & $24(35.3)$ & & & \\
\hline Leisure-time physical activity & & & & & & & 0.4 & 0.4 & 0.9 \\
\hline None & $36(35.3)$ & $14(35.0)$ & $22(35.5)$ & $33(30.0)$ & $10(23.8)$ & $23(33.8)$ & & & \\
\hline Light $\left(<2 \mathrm{~h}_{\text {week }}{ }^{-1}\right)$ & $22(21.6)$ & $8(20.0)$ & $14(22.6)$ & $25(22.7)$ & $7(16.7)$ & $18(26.5)$ & & & \\
\hline Intense $\left(>2 \mathrm{~h}\right.$ week $\left.^{-1}\right)$ & $44(43.1)$ & $18(45.0)$ & $26(41.9)$ & $52(47.3)$ & $25(59.5)$ & $27(39.7)$ & & & \\
\hline Depression scale & $4.5 \pm 3.3$ & $3.6 \pm 3.4$ & $5.1 \pm 3.2$ & $4.8 \pm 3.3$ & $3.6 \pm 2.7$ & $5.5 \pm 3.5$ & 0.6 & 0.7 & 0.7 \\
\hline Anxiety scale & $8.8 \pm 4.2$ & $7.4 \pm 4.4$ & $9.7 \pm 3.4$ & $8.7 \pm 4.2$ & $7.3 \pm 3.9$ & $9.5 \pm 4.1$ & 0.7 & 0.9 & 0.7 \\
\hline
\end{tabular}

MED - Mediterranean; CDPA - Centre for Detection and Prevention of Arteriosclerosis; AHA - American Heart Association. 
This protocol was repeated at 3 and 12 months except for the sociodemographic questionnaire. The nutritional markers were also measured at 6 and 9 months to better check compliance.

\section{Sampling and biochemical metbods}

Fasting (after an overnight fast) and post-prandial (2.5 and $5.0 \mathrm{~h}$ after intake of the test meal) blood samples were collected in dry tubes and in tubes containing ethylenediaminetetraacetic acid. Plasma and serum samples were separated immediately from whole blood by centrifugation $\left(10^{\circ} \mathrm{C}, 10 \mathrm{~min}, 910 \mathrm{~g}\right)$.

The triglyceride-rich lipoprotein (TRL) fraction $\left(S_{\mathrm{f}}=20-400\right)$ was isolated by ultracentrifugation, as previously described $^{21}$.

Triglycerides, phospholipids and total cholesterol concentrations in plasma or TRL fractions were determined by enzymatic procedures with commercial kits (Boehringer Mannheim, Meylan, France). High-density lipoprotein (HDL) cholesterol was measured after sodium phosphotungstate-magnesium chloride precipitation. Low-density lipoprotein (LDL) cholesterol was estimated indirectly by use of the Friedewald formula.

Serum apolipoproteins (apo) A-I, B and E were assayed by immunonephelometry using commercial kits (Behring Werke AG, Marburg, Germany) on a BN100 nephelometer. Serum apoB-48 concentration was assessed by a competitive enzyme-linked immunosorbent assay method ${ }^{21}$. Serum apoC-III concentration was determined using a Hydragel LpC-III kit (Sebia, Issy-les-Moulineaux, France).

To determine plasma fatty acid composition, lipids were extracted from plasma according to the method of Bligh and Dyer $^{22}$. Fatty acid methyl esters were prepared and analysed by gas chromatography on a Perkin-Elmer Autosystem XL equipped with a flameionisation detector.

Carotenoids in plasma were extracted and quantified by reversed-phase high-performance liquid chromatography (HPLC) using a single detector ${ }^{23}$.

The Folin-Ciocalteu method was used to measure total polyphenols present in plasma ${ }^{24}$. A correction was carried out with polyvinylpyrrolidone in order to eliminate the non-phenolic reducing compounds that react with the Folin reagent.

Vitamin $\mathrm{B}_{12}$ and folate were determined using commercial kits (Boehringer Mannheim) on the Roche Elecsys 2010 immunoassay analyser.

Plasma total homocysteine was determined using the Bio-Rad HPLC method (Bio-Rad Laboratories GmbH, Munich, Germany).

Fibrinogen was measured ${ }^{25}$ with reagents (Fibriprest Automate) and reference material obtained from Diagnostica Stago (Asnières, France). Commercially available kits were used for determination of PAI-1 antigen (plasminogen activator inhibitor-1 antigen) (Asserachrom PAI-1; Diagnostica Stago) and tPA antigen (tissue plasminogen activator antigen) (Coaliza t-PA; tPA antigen from Chromogenix, Sweden).

\section{Molecular biology methods}

Peripheral venous blood was used for DNA extraction. Nucleated blood circulating cells were isolated according to the standard Ficoll-Hypaque method (Amersham Biosciences, Freiburg, Germany) and lysed in the presence of proteinase $\mathrm{K}\left(50 \mathrm{mg} \mathrm{ml}^{-1}\right)$ and $1 \%$ sodium dodecylsulphate. DNA was extracted by the phenolchloroform method, followed by precipitation with $70 \%$ ethanol. Polymerase chain reaction was performed in the presence of $100 \mathrm{ng}$ genomic DNA, 2.5 U Taq polymerase (Life Technologies, Cergy-Pontoise, France) and specific pairs of primers (10 $\mu \mathrm{M}$ each). Analyses of amplification products were performed by digestion with specific restriction enzymes and subsequent electrophoresis on $2 \%$ agarose or $8 \%$ polyacrylamide gels. The first set of gene polymorphisms studied is the following: apoA-IV (Ser347 $\mathrm{A} \rightarrow \mathrm{T}), \operatorname{apoB}(-516 \mathrm{C} \rightarrow \mathrm{T})$, apoC-III $\left(3^{\prime} \mathrm{NC} 3175 \mathrm{C} \rightarrow \mathrm{G}\right)$, apoE $($ Cys112 $\mathrm{T} \rightarrow \mathrm{C}, \operatorname{Arg} 158 \mathrm{C} \rightarrow \mathrm{T}$ ), cholesterol ester transfer protein $(779 \mathrm{G} \rightarrow \mathrm{A})$, hepatic lipase $(-480$ $\mathrm{C} \rightarrow \mathrm{T}$ ), intestinal fatty acid binding protein (IFABP) $($ Ala5 $4 \mathrm{G} \rightarrow \mathrm{A})$, lipoprotein lipase $(\mathrm{LPL})(-93 \mathrm{G} \rightarrow \mathrm{T})$ and microsomal transfer triglyceride protein $(-493 \mathrm{G} \rightarrow \mathrm{T})$. Some other relevant polymorphisms might be determined in the future.

\section{Statistical analysis}

The results will be analysed on the basis of intention to treat. Baseline statistical analysis was performed using the SPSS statistical package (SPSS Inc., Chicago, IL, USA). Chisquare tests or analyses of variance were used to compare socio-economic characteristics, risk factors, dietary intakes and biological markers of the subjects in the two arms at enrolment.

Adjustment for energy and variables that differed between the two arms was performed. As the significance of the difference was not modified by adjustments for the other variables, only the $P$-value adjusted for energy is shown.

Spearman rank correlations were used because they are less influenced by outlying values and are more robust in meeting normality assumptions. Multivariate analyses were done when adjustment was used. Because essential polyunsaturated fatty acids (linoleic acid, eicosapentaenoic acid (EPA) and docosahexaenoic acid (DHA)) are not yet included in the REGAL database, we used the relevant food intake in $\mathrm{g} \mathrm{day}^{-1}$ (sunflower oil for linoleic acid, fish for EPA and DHA) to estimate the correlation between these biological markers and dietary intake.

\section{Results}

In total, 232 subjects were invited to participate in the study between December 1998 (beginning of the study) 
and April 2002. Among them, eight refused and 12 were excluded, leaving 212 subjects included in the study.

\section{Baseline characteristics}

The MED arm finally constituted 40 men and 62 women $(n=102)$ and the CDPA/AHA arm, 42 men and 68 women $(n=110)$. There was no significant difference between the MED and CDPA/AHA arms with regard to sex, age, physical activity and marital status (Table 4). There was a borderline significant difference between the MED and CDPA/AHA women with regard to occupational status.

There was no significant difference in the distribution of the genotypes of apoA-IV $(P=0.9)$, apoB $(P=0.5)$, apoE $(P=0.3)$, IFABP $(P=0.8)$ and LPL $(P=0.3)$ between the two arms (data not shown).

There was a borderline significant difference for the proportion of current smokers (slightly more in the MED arm) and ex-smokers (more in the CDPA/AHA arm), mainly in women (Table 5).

There was no difference in Framingham risk score ${ }^{26}$ between the MED and CDPA/AHA arms, but there were significant differences with regard to fasting total cholesterol, HDL cholesterol, LDL cholesterol, apoA-I, apoB and homeostasis model of assessment (HOMA) score ${ }^{27}$ (Table 6). These differences seem to be due to differences between the groups of women, with significantly higher values for total cholesterol, LDL cholesterol, apoB and HOMA score in the women in the MED group, whereas HDL cholesterol was lower in this group. The difference in HDL cholesterol disappeared after adjustment for age, alcohol consumption and tobacco use, while the difference in total cholesterol and LDL cholesterol remained significant after adjustment (data not shown). Adjustment for tobacco use and alcohol consumption suppressed the minor difference between apoB levels in men. In women, adjustment for menopausal status negated the significant difference between apoB levels, whereas the adjustment had no effect on the cholesterol level difference.

In both arms, fat and protein intakes were high while carbohydrate and fibre intakes were low (Table 7). There was no significant difference between the MED and CDPA/AHA arms with regard to nutritional intake, except for vitamin C intake, which was significantly higher in the MED group of men. This difference remained after adjustment for total energy intake, tobacco use and occupational status. This sub-sample also showed a borderline significantly lower intake of polyunsaturated lipids $\left(\mathrm{g} \mathrm{day}^{-1}\right)$ and a lower ratio of polyunsaturated lipids to saturated lipids.

Overall, the nutritional markers were comparable in both arms with few exceptions (Table 8). There was a significant difference in $\alpha$-carotene plasma levels between men in the two arms, which remained after adjustment for age, tobacco use and occupational status (data not shown), the level of plasma $\alpha$-carotene being higher in CDPA/AHA men than in MED men.

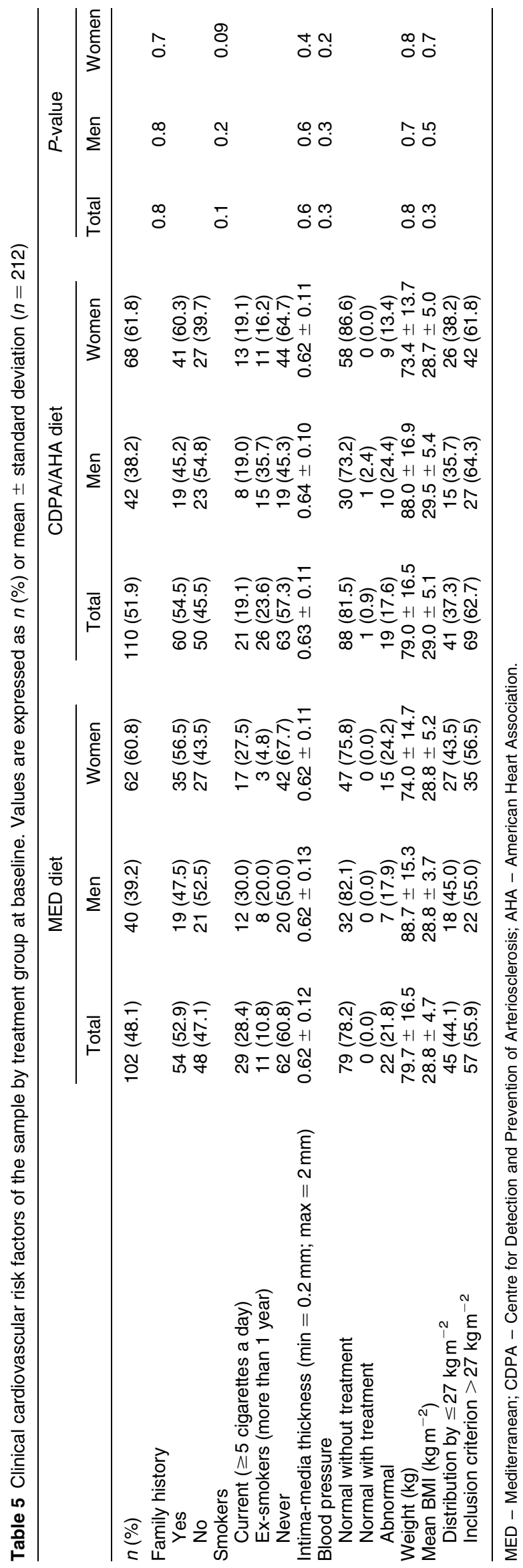


Table 6 Cardiovascular risk factors of the sample by treatment group at baseline. Values are expressed as $n(\%)$ or mean \pm standard deviation $(n=212)$

\begin{tabular}{|c|c|c|c|c|c|c|c|c|c|}
\hline & \multicolumn{3}{|c|}{ MED diet } & \multicolumn{3}{|c|}{ CDPA/AHA diet } & \multicolumn{3}{|c|}{$P$-value } \\
\hline & Total & Men & Women & Total & Men & Women & Total & Men* & Women† \\
\hline$n(\%)$ & $102(48.1)$ & 40 (39.2) & $62(60.8)$ & $110(51.9)$ & $42(38.2)$ & $68(61.8)$ & & & \\
\hline $\begin{array}{c}\text { ApoA-I }\left(g^{-1}\right) \\
(n=210)\end{array}$ & $1.4 \pm 0.3$ & $1.3 \pm 0.3$ & $1.5 \pm 0.3$ & $1.6 \pm 0.3$ & $1.4 \pm 0.2$ & $1.6 \pm 0.3$ & 0.2 & 0.1 & 0.6 \\
\hline $\begin{array}{c}\text { ApoB }\left(\mathrm{gl}^{-1}\right) \\
(n=210)\end{array}$ & $1.3 \pm 0.2$ & $1.3 \pm 0.2$ & $1.3 \pm 0.2$ & $1.2 \pm 0.2$ & $1.2 \pm 0.2$ & $1.2 \pm 0.2$ & 0.02 & $0.07(0.1)$ & $0.01(0.3)$ \\
\hline $\begin{array}{l}\text { ApoB-48 } \\
\quad\left(\mu \mathrm{g} \mathrm{ml}^{-1}\right)(n=201)\end{array}$ & $0.2 \pm 0.2$ & $0.3 \pm 0.2$ & $0.2 \pm 0.2$ & $0.2 \pm 0.2$ & $0.3 \pm 0.2$ & $0.2 \pm 0.2$ & 0.9 & 0.4 & 0.5 \\
\hline $\begin{array}{l}\text { ApoC-III }\left(\mathrm{mgl}^{-1}\right) \\
(n=195)\end{array}$ & $27.3 \pm 7.6$ & $27.1 \pm 8.6$ & $27.4 \pm 7.0$ & $28.7 \pm 7.5$ & $30.3 \pm 8.8$ & $27.7 \pm 6.4$ & 0.1 & 0.06 & 0.8 \\
\hline $\begin{array}{c}\text { ApoE }\left(\mathrm{mgl}^{-1}\right) \\
(n=208)\end{array}$ & $41.6 \pm 11.8$ & $41.6 \pm 3.4$ & $41.6 \pm 10.9$ & $44.0 \pm 27.0$ & $46.0 \pm 39.8$ & $42.8 \pm 14.5$ & 0.9 & 0.8 & 0.8 \\
\hline $\begin{array}{l}\text { Cholesterol } \\
\quad\left(\mathrm{mmol}^{-1}\right)(n=212)\end{array}$ & $6.6 \pm 1.0$ & $6.4 \pm 1.0$ & $6.8 \pm 1.0$ & $6.3 \pm 0.9$ & $6.3 \pm 0.9$ & $6.3 \pm 0.9$ & 0.03 & 0.7 & 0.01 \\
\hline $\begin{array}{l}\text { HDL cholesterol } \\
\qquad\left(\mathrm{mmoll}^{-1}\right)(n=212)\end{array}$ & $1.5 \pm 0.4$ & $1.3 \pm 0.3$ & $1.5 \pm 0.4$ & $1.6 \pm 0.5$ & $1.4 \pm 0.4$ & $1.8 \pm 0.5$ & 0.01 & 0.08 & 0.04 \\
\hline $\begin{array}{l}\text { LDL cholesterol } \\
\qquad\left(\mathrm{mmol}^{-1}\right)(n=206)\end{array}$ & $4.4 \pm 0.9$ & $4.2 \pm 1.0$ & $4.6 \pm 0.9$ & $4.0 \pm 0.9$ & $4.0 \pm 0.9$ & $4.0 \pm 0.9$ & 0.003 & 0.2 & 0.005 \\
\hline $\begin{array}{l}\text { Triglycerides } \\
\quad\left(\mathrm{mmoll}^{-1}\right)(n=212)\end{array}$ & $1.6 \pm 1.0$ & $2.0 \pm 1.2$ & $1.3 \pm 0.6$ & $1.5 \pm 1.4$ & $1.9 \pm 1.7$ & $1.3 \pm 1.0$ & 0.09 & 0.4 & 0.2 \\
\hline $\begin{array}{l}\text { Homocysteine } \\
\quad\left(\mathrm{mmoll}^{-1}\right)(n=191)\end{array}$ & $10.7 \pm 3.2$ & $12.1 \pm 3.3$ & $9.8 \pm 2.9$ & $10.6 \pm 2.9$ & $11.5 \pm 2.7$ & $9.9 \pm 2.8$ & 0.8 & 0.4 & 0.8 \\
\hline $\begin{array}{l}\text { tPA antigen } \\
\quad\left(\mathrm{ng} \mathrm{ml}^{-1}\right)(n=211)\end{array}$ & $8.3(2.9)$ & $9.2(2.8)$ & $7.6(2.8)$ & $8.1(2.6)$ & $9.0(2.5)$ & $7.5(2.4)$ & 0.8 & 0.9 & 0.8 \\
\hline $\begin{array}{l}\text { Fibrinogen }\left(\mathrm{gl}^{-1}\right) \\
\quad(n=211)\end{array}$ & $3.6(0.7)$ & $3.4(0.7)$ & $3.7(0.6)$ & $3.7(0.7)$ & $3.5(0.7)$ & $3.8(0.6)$ & 0.5 & 0.4 & 0.8 \\
\hline $\begin{array}{l}\text { PAl-1 antigen } \\
\quad\left(\mathrm{ng} \mathrm{ml}^{-1}\right)(n=211)\end{array}$ & $48.1(33.8)$ & $60.9(41.6)$ & $40.1(25.0)$ & $48.8(39.1)$ & $57.4(50.0)$ & $43.5(29.8)$ & 0.8 & 0.7 & 0.4 \\
\hline $\begin{array}{l}\text { Framingham risk } \\
\quad \text { score } \neq(n=212)\end{array}$ & & $5.7(2.8)$ & $4.2(6.4)$ & & $5.5(2.5)$ & $3.7(5.9)$ & & 0.8 & 0.7 \\
\hline $\begin{array}{l}\text { HOMA score } \\
\quad(n=162)\end{array}$ & $2.6(1.8)$ & $2.6(1.2)$ & $2.7(2.2)$ & $2.1(1.4)$ & $2.3(1.5)$ & $2.0(1.3)$ & 0.04 & 0.4 & 0.06 \\
\hline
\end{tabular}

MED - Mediterranean; CDPA - Centre for Detection and Prevention of Arteriosclerosis; AHA - American Heart Association; apo - apolipoprotein; HDL high-density lipoprotein; LDL - low-density lipoprotein; tPA - tissue plasminogen activator; PAl-1 - plasminogen activator inhibitor-1; HOMA - homeostasis model of assessment.

* With adjustment for tobacco use and alcohol consumption in parentheses.

† With adjustment for menopause in parentheses.

¥Framingham risk score is an algorithm that results in a calculated score to predict the 10 -year risk of coronary artery disease in persons aged 30 to 74 years ${ }^{41}$. This algorithm was established using recommended guidelines for blood pressure, total cholesterol and HDL cholesterol in addition to age, smoking history and history of diabetes. To calculate the score for a subject, points were assigned for each risk factor and age category, and for smoking and diabetes history. Points range from lowest for least risk to highest for greatest risk.

$\S$ HOMA score ${ }^{42}=\left[\right.$ fasting serum insulin $\left(\mu \mathrm{Uml}^{-1}\right) \times$ fasting plasma glucose $\left.\left(\mathrm{mmol}^{-1}\right)\right] / 22.5$.

Regarding plasma fatty acids, stearic acid was significantly higher in the CDPA/AHA arm than in the MED arm and remained borderline significant after adjustment for age, tobacco use and occupational status (data not shown). There was also slightly more linolenic acid in the MED women and di-homo $\gamma$-linolenic acid in the CDPA/AHA men, but these slight differences disappeared after adjustment for age, tobacco use and occupational status.

\section{Correlation between nutritional intakes and plasma nutrient levels}

Regarding plasma carotenoids we found a weak correlation between total carotene intake and $\alpha$-carotene plasma level $(r=0.18, P=0.013)$. The correlations between carotenoid intakes and fasting plasma carotenoid levels were higher in both groups of women: total carotenoids $r=0.20, \quad P<0.05 ; \quad \alpha$-carotene $r=0.23$,
$P<0.05 ; \beta$-carotene $r=0.19, P<0.05$; and $\beta$-cryptoxanthin $r=0.35, P<0.01$.

A correlation between dietary folate intake and plasma folate in men and women $(r=0.47, P<0.01$ and $r=0.30, P<0.05$, respectively) and an inverse correlation between plasma homocysteine and plasma folate in men $(r=-0.24, P<0.05)$ were observed. Multivariate analysis showed an association between homocysteine level and dietary folate intake $\left(r^{2}=0.17, P<0.01\right.$, after adjustment for sex, age and total energy intake).

With regard to lipid parameters, only one saturated fatty acid, palmitic acid ( $r=0.17, P<0.05$ ), was positively and significantly correlated with dietary cholesterol, whereas DHA $(r=-0.16, P<0.05)$ and HDL cholesterol $(r=-0.22, \quad P=0.001)$ were negatively and significantly correlated with dietary cholesterol. Finally, a weak correlation between fish intake and EPA 


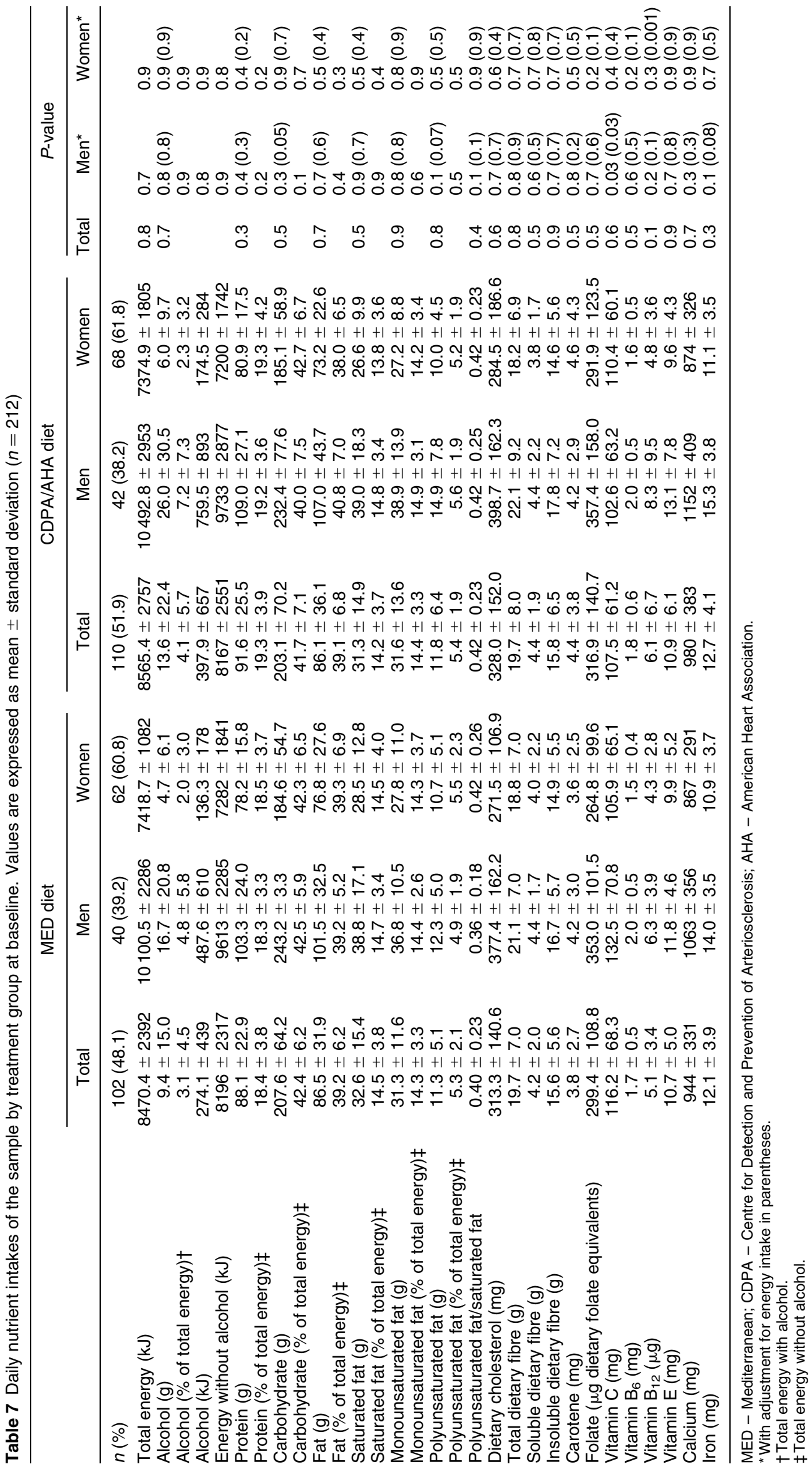


Table 8 Plasma nutritional markers of the sample by treatment group at baseline. Values are expressed as mean \pm standard deviation $(n=212)$

\begin{tabular}{|c|c|c|c|c|c|c|c|c|c|}
\hline & \multicolumn{3}{|c|}{ MED diet } & \multicolumn{3}{|c|}{ CDPA/AHA diet } & \multicolumn{3}{|c|}{$P$-value } \\
\hline & Total & Men & Women & Total & Men & Women & Total & Men & Women \\
\hline$n(\%)$ & $102(48.1)$ & $40(39.2)$ & $62(60.8)$ & $110(51.9)$ & $42(38.2)$ & $68(61.8)$ & & & \\
\hline $\begin{array}{l}\beta \text {-Carotene }\left(\mu \mathrm{molI}^{-1}\right) \\
\alpha \text {-Carotene }\left(\mu \mathrm{moll}^{-1}\right) \\
\beta \text {-Cryptoxanthin }\left(\mu \mathrm{mol} \mathrm{I}^{-1}\right) \\
\text { Lycopene }\left(\mu \mathrm{mol} \mathrm{I}^{-1}\right) \\
\text { Lutein }\left(\mu \mathrm{moll} \mathrm{I}^{-1}\right) \\
\text { Zeaxanthin }\left(\mu \mathrm{molI}^{-1}\right) \\
\text { Folate }\left(\mu \mathrm{gl} \mathrm{I}^{-1}\right) \\
\text { Phenolic compounds } \\
\quad\left(\mathrm{mmolI}^{-1}\right)(n=211)\end{array}$ & $\begin{array}{l}0.60 \pm 0.57 \\
0.19 \pm 0.19 \\
0.32 \pm 0.30 \\
0.53 \pm 0.40 \\
0.86 \pm 0.76 \\
0.11 \pm 0.06 \\
5.7 \pm 2.1 \\
0.29 \pm 0.14\end{array}$ & $\begin{array}{l}0.44 \pm 0.49 \\
0.11 \pm 0.10 \\
0.29 \pm 0.27 \\
0.55 \pm 0.40 \\
0.91 \pm 0.76 \\
0.11 \pm 0.08 \\
5.6 \pm 2.3 \\
0.29 \pm 0.13\end{array}$ & $\begin{aligned} 0.74 & \pm 0.61 \\
0.19 & \pm 0.19 \\
0.40 & \pm 0.34 \\
0.51 & \pm 0.38 \\
0.80 & \pm 0.76 \\
0.11 & \pm 0.06 \\
5.7 & \pm 2.0 \\
0.26 & \pm 0.14\end{aligned}$ & $\begin{array}{l}0.67 \pm 0.57 \\
0.19 \pm 0.19 \\
0.38 \pm 0.36 \\
0.53 \pm 0.38 \\
0.91 \pm 0.76 \\
0.11 \pm 0.06 \\
6.1 \pm 2.7 \\
0.26 \pm 0.14\end{array}$ & $\begin{array}{l}0.42 \pm 0.19 \\
0.17 \pm 0.10 \\
0.27 \pm 0.19 \\
0.57 \pm 0.57 \\
0.86 \pm 0.76 \\
0.11 \pm 0.06 \\
6.0 \pm 2.2 \\
0.29 \pm 0.17\end{array}$ & $\begin{array}{c}0.82 \pm 0.57 \\
0.19 \pm 0.19 \\
0.46 \pm 0.38 \\
0.51 \pm 0.19 \\
0.95 \pm 0.95 \\
0.13 \pm 0.06 \\
6.1 \pm 3.2 \\
0.25 \pm 0.14\end{array}$ & $\begin{array}{l}0.2 \\
0.3 \\
0.7 \\
0.4 \\
0.5 \\
0.3 \\
0.6 \\
0.2\end{array}$ & $\begin{array}{l}0.2 \\
0.02 \\
0.7 \\
0.7 \\
0.7 \\
0.8 \\
0.5 \\
0.2\end{array}$ & $\begin{array}{l}0.4 \\
0.8 \\
0.6 \\
0.4 \\
0.2 \\
0.2 \\
0.9 \\
0.6\end{array}$ \\
\hline \multicolumn{10}{|l|}{ Fatty acids ( $\%$ of total) } \\
\hline C16:0 & $24.4 \pm 3.5$ & $25.3 \pm 3.4$ & $23.8 \pm 3.4$ & $23.5 \pm 3.2$ & $24.0 \pm 3.2$ & $23.2 \pm 3.2$ & 0.06 & 0.8 & 0.3 \\
\hline $\mathrm{C} 16: 1 n-9$ & $2.7 \pm 1.1$ & $2.5 \pm 1.0$ & $2.8 \pm 1.2$ & $2.5 \pm 0.9$ & $2.4 \pm 0.9$ & $2.6 \pm 0.9$ & 0.4 & 0.7 & 0.4 \\
\hline C18:0 & $6.5 \pm 1.6$ & $6.1 \pm 1.6$ & $6.7 \pm 1.5$ & $7.0 \pm 1.5$ & $6.9 \pm 1.5$ & $7.1 \pm 1.5$ & 0.02 & 0.04 & 0.3 \\
\hline $\mathrm{C} 18: 1 n-9$ & $20.7 \pm 3.1$ & $21.8 \pm 3.1$ & $20.0 \pm 2.9$ & $20.5 \pm 3.4$ & $21.1 \pm 3.8$ & $20.1 \pm 3.0$ & 0.6 & 0.4 & 0.8 \\
\hline C18:2n-6 & $28.2 \pm 5.2$ & $27.6 \pm 4.6$ & $28.7 \pm 5.6$ & $28.5 \pm 3.9$ & $28.1 \pm 3.7$ & $28.7 \pm 4.1$ & 0.5 & 0.5 & 0.8 \\
\hline$C 18: 3 n-3$ & $0.3 \pm 0.4$ & $0.3 \pm 0.3$ & $0.4 \pm 0.4$ & $0.3 \pm 0.3$ & $0.4 \pm 0.3$ & $0.3 \pm 0.2$ & 0.5 & 0.4 & $0.1^{*}$ \\
\hline C18:4 & $0.07 \pm 0.1$ & $0.09 \pm 0.1$ & $0.06 \pm 0.1$ & $0.07 \pm 0.1$ & $0.07 \pm 0.2$ & $0.07 \pm 0.1$ & 0.8 & 0.6 & 0.9 \\
\hline $\mathrm{C} 20: 3 n-6$ & $1.5 \pm 0.7$ & $1.4 \pm 0.7$ & $1.6 \pm 0.8$ & $1.6 \pm 0.6$ & $1.5 \pm 0.6$ & $1.7 \pm 0.6$ & 0.4 & $0.09^{*}$ & 0.9 \\
\hline $\mathrm{C} 20: 4 n-6$ & $7.1 \pm 1.9$ & $6.8 \pm 2.0$ & $7.3 \pm 1.8$ & $7.3 \pm 1.7$ & $6.8 \pm 1.5$ & $7.5 \pm 1.7$ & 0.7 & 0.8 & 0.9 \\
\hline $\mathrm{C} 20: 5 n-3$ & $0.8 \pm 0.6$ & $0.8 \pm 0.5$ & $0.8 \pm 0.7$ & $0.9 \pm 1.0$ & $0.8 \pm 0.5$ & $1.0 \pm 1.2$ & 0.6 & 0.5 & 0.9 \\
\hline $\mathrm{C} 22: 6 n-3$ & $2.4 \pm 0.9$ & $2.3 \pm 0.9$ & $2.5 \pm 1.0$ & $2.6 \pm 1.1$ & $2.4 \pm 1.0$ & $2.8 \pm 1.2$ & 0.3 & 0.8 & 0.3 \\
\hline
\end{tabular}

MED - Mediterranean; CDPA - Centre for Detection and Prevention of Arteriosclerosis; AHA - American Heart Association.

*Non-significantly different after adjustment for age, tobacco use and occupational status.

$(r=0.15, P<0.05)$ was observed, but not with plasma DHA level.

\section{Discussion}

The Medi-RIVAGE study is an intervention study that uses a global nutritional approach to test the effect of an updated traditional Mediterranean diet (olive oil being the predominant added fat), compared with a usual AHA-type diet, on risk factors of CVD for primary prevention in atrisk subjects. In fact, as shown during previous studies on populations living in the French Mediterranean area, the traditional Mediterranean diet tends to disappear ${ }^{11,12}$.

So far, the Lyon Diet Heart study ${ }^{28,29}$ has been the only intervention study comparing a Mediterranean diet with the usual prescribed diet. Nevertheless, it was a secondary prevention study, with patients who had previously suffered from myocardial infarction. Furthermore, in that study, the diet included an $\alpha$-linolenic acid-enriched margarine. In this line, the MARGARIN (Mediterranean Alpha-linolenic Enriched Groningen Dietary Intervention) study was begun in $1998^{30,31}$. It was a primary prevention study with high-risk subjects where the authors evaluated the effects of $\alpha$-linolenic acid-enriched margarine and the effects of an intensive group education programme. Whereas the total sample reached the minimum required size and very few subjects refused to participate in the study protocol, most visiting subjects were under drug therapy and, thus, not included.
Differences between the CDPA/AHA and MED diets appear to be of both qualitative and quantitative importance. Because differences between the protocols of the two arms were very limited, it will thus be possible largely to attribute any further differences observed to the difference between the diets per se.

The characteristics of the men in the two arms were quite comparable. There were some differences between the women in both arms, mainly concerning occupational status, HOMA score and cholesterol-related parameters, despite appropriate randomisation. These differences will be taken into account when comparing effects of the diets in the follow-up analysis.

The allelic distributions of the gene polymorphisms studied (apoA-IV, apoB, apoE, IFABP and LPL) were comparable overall to those found in other studies, with no difference between the two arms ${ }^{32-34}$.

The total energy intake of the subjects at enrolment (Table 7) was in agreement with nutritional guidelines ${ }^{35}$ and comparable to that found in other studies, especially one in a French Mediterranean population (LanguedocRoussillon region) ${ }^{36}$.

Nevertheless, the part of energy provided by saturated fatty acids clearly departed from nutritional guidelines and was almost twice the recommended intake ${ }^{35}$. Polyunsaturated fatty acid intake was also high whereas monounsaturated fatty acid intake was insufficient (Table 7), as found in a French south-west cohort in the MONICA project $^{37}$, in another Mediterranean population (the 
Languedoc-Roussillon MEDHEA study) ${ }^{36}$ and in a national population sample (SU.VI.MAX; SUpplementation en VItamines et Minéraux AntioXydants study) ${ }^{38}$.

Although insufficient according to French nutritional guidelines $\left(>25 \mathrm{~g} \mathrm{day}^{-1}\right)^{35}$, the fibre intake in the MediRIVAGE population (21-22 and 18-19 $\mathrm{g} \mathrm{day}^{-1}$ in men and women, respectively) is comparable to that of other French southern populations $\left(24 \mathrm{~g} \mathrm{day}^{-1}\right.$ for $\mathrm{MONICA}^{37}$ and MEDHEA cohorts ${ }^{36}$ ).

For most vitamins and antioxidants (vitamins $\mathrm{C}$ and E, carotenoids) similar intake patterns were observed, with more vitamins and antioxidants in the southern populations than in the nation-wide SU.VI.MAX sample (e.g. vitamin C for men: Medi-RIVAGE, $117 \mathrm{mg} \mathrm{day}^{-1}$; MEDHEA, $108.2 \mathrm{mg} \mathrm{day}^{-1}$; SU.VI.MAX, $92 \mathrm{mg} \mathrm{day}^{-1}$ ).

The plasma $\alpha$ - and $\beta$-carotene levels found in MediRIVAGE are lower than those found in southern France in the early $1990 s^{39}$ and higher than the level found in Spain $^{40}$ for lycopene, $\alpha$ - and $\beta$-carotene, but lower for lutein and zeaxanthin.

The validity of the nutritional intake assessment was estimated by correlations between nutritional markers (carotenoids, folate, EPA and DHA fatty acids) (Table 8) and the recorded intake of relevant nutrients (Table 7 ) or foods. The correlation found between plasma carotene and carotene intake $(r=0.18, P<0.05)$ is comparable to the one found in a previous French Mediterranean study ${ }^{10}$. In the European Prospective Investigation into Cancer and Nutrition (EPIC study), variable correlation coefficients between $\beta$-carotene intake and plasma $\beta$-carotene level were found across the populations studied ${ }^{41}$ : i.e. in German women $(r=0.27)$ and men $(\mathrm{r}=0.48)$, Italian women $(r=0.27)$ and men $(r=0.34)$, and Dutch women $(r=0.18)$ and men $(r=-0.13)$.

A significant direct association between plasma folate level and folate intake was observed, as well as an inverse association between plasma homocysteine and folate intake, as previously shown ${ }^{42}$. Plasma homocysteine level being a risk factor for CVD, it was important to assess this relationship accurately.

In contrast, we did not find any correlation between total or soluble fibre intake and plasma cholesterol level as shown in other studies ${ }^{10,43}$. Moreover, we did not find any association between dietary saturated fatty acid and plasma cholesterol level ${ }^{4,6}$, an observation that could be due to the moderately low intake of saturated fatty acid in our region compared with Northern European countries or North America. That we performed serum fatty acid measurements instead of erythrocyte measurements might explain why the correlation coefficient between fish intake and EPA is rather low, compared with the results of Gerber et al. ${ }^{10}$.

In conclusion, the comparability of the two arms with regard to sociodemographic factors and most CVD risks is notable and warrants a low risk of biases. However, it will be necessary to adjust for sex when analysing the total sample and to take into account the difference in cholesterol level between the two arms at enrolment.

The assessment of nutritional intake has been validated by the correlations obtained between dietary intake and relevant biomarkers. This is especially important to estimate the compliance of the participants, which is an essential factor for the interpretation of the results.

The nutritional baseline assessment also clearly demonstrates that fatty acids are not well balanced and that fibre intake is insufficient in this Mediterranean population, whereas micronutrients are satisfactory overall. Thus, changes in the intakes of fatty acids and fibre upon intervention might induce quantifiable changes in risk factors. Further papers reporting on the effects of the intervention protocol will provide new data on the feasibility and health-promoting properties of the diets studied, as well as interactions with gene polymorphisms.

\section{Acknowledgements}

The authors would like to acknowledge the skills of CDPA dietitians (N Rousset and S Loviconi), laboratory supervisors (MF Alliaud, AM Lorec) and laboratories technicians (M Senft, J Leonardi, B Lyan, C Bideau, D Iniesta, N Peyrol and JF Lesgard); financial support from the French Research Ministry (AQS grant, S.V. salary), INSERM (IDS grant), Provence-Alpes-Cote d'Azur Regional Council, Bouches du Rhône General Council; and the following companies: Rivoire \& Carret Lustucru, Jean Martin, Boulangerie Coagulation Surgelés, Distplack Mariani and Minoterie Giraud.

\section{References}

1 Lopez AD. Assessing the burden of mortality from cardiovascular diseases. World Health Statistics Quarterly 1993; 46: 91-6.

2 Murray CJ, Lopez AD. Global mortality, disability, and the contribution of risk factors: Global Burden of Disease Study. Lancet 1997; 349: 1436-42.

3 Keys A, Blackburn HW, Menotti A, Karvonen MJ, Aravanis C, Blackburn $\mathrm{H}$, et al. Coronary heart disease in seven countries. Summary. Circulation 1970; 41: I186-95.

4 Keys A, Menotti A, Karvonen MJ, Aravanis C, Blackburn H, Buzina R, et al. The diet and 15-year death rate in the seven countries study. American Journal of Epidemiology 1986; 124: 903-15.

5 Menotti A, Blackburn H, Kromhout D, Nissinen A, Fidanza F, Giampaoli S, et al. Changes in population cholesterol levels and coronary heart disease deaths in seven countries. European Heart Journal 1997; 18: 566-71.

6 Hu FB, Willett WC. Diet and coronary heart disease: findings from the Nurses' Health Study and Health Professionals' Follow-up Study. Journal of Nutrition, Health \& Aging 2001; 5: $132-8$.

7 Tunstall-Pedoe H, Kuulasmaa K, Amouyel P, Arveiler D, Rajakangas AM, Pajak A. Myocardial infarction and coronary 
deaths in the World Health Organization MONICA Project. Registration procedures, event rates, and case-fatality rates in 38 populations from 21 countries in four continents. Circulation 1994; 90: 583-612.

8 Kushi LH, Lenart EB, Willett WC. Health implications of Mediterranean diets in light of contemporary knowledge. 2. Meat, wine, fats, and oils. American Journal of Clinical Nutrition 1995; 61: 1416S-27S.

9 Trichopoulou A, Kouris-Blazos A, Wahlqvist ML, Gnardellis C, Lagiou P, Polychronopoulos E, et al. Diet and overall survival in elderly people. British Medical Journal 1995; 311: $1457-60$.

10 Gerber MJ, Scali JD, Michaud A, Durand MD, Astre CM, Dallongeville $\mathrm{J}$, et al. Profiles of a healthful diet and its relationship to biomarkers in a population sample from Mediterranean southern France. Journal of the American Dietetic Association 2000; 100: 1164-71.

11 Scali J, Richard A, Gerber M. Diet profiles in a population sample from Mediterranean southern France. Public Health Nutrition 2001; 4: 173-82.

12 Ferro-Luzzi A, James WP, Kafatos A. The high-fat Greek diet: a recipe for all? European Journal of Clinical Nutrition 2002; 56: 796-809.

13 Stephens NG, Parsons A, Schofield PM, Kelly F, Cheeseman K, Mitchinson MJ. Randomised controlled trial of vitamin $\mathrm{E}$ in patients with coronary disease: Cambridge Heart Antioxidant Study (CHAOS). Lancet 1996; 347: 781-6.

14 Dietary supplementation with $n-3$ polyunsaturated fatty acids and vitamin $\mathrm{E}$ after myocardial infarction: results of the GISSI-Prevenzione trial. Gruppo Italiano per lo Studio della Sopravvivenza nell'Infarto miocardico. Lancet 1999; 354 : 447-55.

15 Yusuf S, Dagenais G, Pogue J, Bosch J, Sleight P. Vitamin E supplementation and cardiovascular events in high-risk patients. The Heart Outcomes Prevention Evaluation Study Investigators. New England Journal of Medicine 2000; 342: 154-60.

16 MRC/BHF Heart Protection Study of antioxidant vitamin supplementation in 20,536 high-risk individuals: a randomised placebo-controlled trial. Lancet 2002; 360: 23-33

17 Traeden UI, Holm L, Sandstrom B, Andersen PK, Jarden M. Effectiveness of a dietary intervention strategy in general practice: effects on blood lipids, health and well-being. Public Health Nutrition 1998; 1: 273-81.

18 Pham TC, Colette C, Monnier L. Communication between regional dietetic software and USDA-SR12. In: Third International Food Data Conference. Back to Basics. Rome: Food and Agriculture Organization, 1999.

19 Favier JC, Ireland-Ripert J, Toque C, Feinberg M. Répertoire général des aliments. Table de composition, 2nd ed. Paris: CIQUAL, 1995.

20 Daures JP, Gerber M, Scali J, Astre C, Bonifacj C, Kaaks R. Validation of a food-frequency questionnaire using multipleday records and biochemical markers: application of the triads method. Journal of Epidemiology and Biostatistics 2000; 5: 109-15.

21 Harbis A, Defoort C, Narbonne H, Juhel C, Senft M, Latge C, et al. Acute hyperinsulinism modulates plasma apolipoprotein B-48 triglyceride-rich lipoproteins in healthy subjects during the postprandial period. Diabetes 2001; 50: 462-9.

22 Bligh EG, Dyer WG. Rapid method extraction and purification. Canadian Journal of Biochemistry and Physiology 1959; 57: 911-7.

23 Lyan B, Azais-Braesco V, Cardinault N, Tyssandier V, Borel P Alexandre-Gouabau MC, et al. Simple method for clinical determination of 13 carotenoids in human plasma using an isocratic high-performance liquid chromatographic method.
Journal of Chromatography B: Biomedical Sciences and Applications 2001; 751: 297-303.

24 Singleton VL, Rossi JA. Colorimetry of total phenolics with phosphomolybdic-phosphotunstic acid reagents. American Journal of Enology and Viticulture 1965; 16: 144-58.

25 Clauss A. Gerinnungphysiologische schnellmethode zur destimmung des fibrinogens. Acta Haematologica 1957; 17: 237-46.

26 Wilson PW, D'Agostino RB, Levy D, Belanger AM, Silbershatz H, Kannel WB. Prediction of coronary heart disease using risk factor categories. Circulation 1998; 97 : $1837-47$

27 Matthews DR, Hosker JP, Rudenski AS, Naylor BA, Treacher DF, Turner RC. Homeostasis model assessment: insulin resistance and beta-cell function from fasting plasma glucose and insulin concentrations in man. Diabetologia 1985; 28: $412-9$.

28 De Lorgeril M, Renaud S, Mamelle N, Salen P, Martin JL, Monjaud I, et al. Mediterranean alpha-linolenic acid-rich diet in secondary prevention of coronary heart disease. Lancet 1994; 343: 1454-9.

29 De Lorgeril M, Salen P, Martin JL, Monjaud I, Delaye J, Mamelle N. Mediterranean diet, traditional risk factors, and the rate of cardiovascular complications after myocardial infarction: final report of the Lyon Diet Heart Study. Circulation 1999; 99: 779-85.

30 Bemelmans WJ, Broer J, de Vries JH, Hulshof KF, May JF, Meyboom-De Jong B. Impact of Mediterranean diet education versus posted leaflet on dietary habits and serum cholesterol in a high risk population for cardiovascular disease. Public Health Nutrition 2000; 3: 273-83.

31 Bemelmans WJ, Broer J, Feskens EJ, Smit AJ, Muskiet FA, Lefrandt JD, et al. Effect of an increased intake of alphalinolenic acid and group nutritional education on cardiovascular risk factors: the Mediterranean Alpha-linolenic Enriched Groningen Dietary Intervention (MARGARIN) study. American Journal of Clinical Nutrition 2002; 75: $221-7$.

32 Frikke-Schmidt R, Nordestgaard BG, Agerholm-Larsen B, Schnohr P, Tybjaerg-Hansen A. Context-dependent and invariant associations between lipids, lipoproteins, and apolipoproteins and apolipoprotein E genotype. Journal of Lipid Research 2000; 41: 1812-22.

33 Baier LJ, Sacchettini JC, Knowler WC, Eads J, Paolisso G, Tataranni PA, et al. An amino acid substitution in the human intestinal fatty acid binding protein is associated with increased fatty acid binding, increased fat oxidation, and insulin resistance. Journal of Clinical Investigation 1995; 95 : 1281-7.

34 Kastelein JJ, Groenemeyer BE, Hallman DM, Henderson H, Reymer PW, Gagne SE, et al. The Asn9 variant of lipoprotein lipase is associated with the $-93 \mathrm{G}$ promoter mutation and an increased risk of coronary artery disease. The Regress Study Group. Clinical Genetics 1998; 53: 27-33.

35 Martin A, Azais-Braesco V, Couet C, Cynober L, Gueguen L, Lairon $\mathrm{D}$, et al. Apports nutritionnels conseillés pour la population française. Paris: Cnerna CNRS, 2001.

36 Gerber M, Siari S, Michaud A, Scali J. Alimentation Méditerranéenne et santé. MEDHEA. Résultats de l'Hérault. Actualité en Diététique 1999; 35: 1391-6.

37 Jost JP, Simon C, Nuttens MC, Bingham A, Ruidavets JB, Cambou JP, et al. Comparison of dietary patterns between population samples in the three French MONICA nutritional surveys. Revue d'Epidemiologie et de Santé Publique 1990; 38: $517-23$.

38 Mennen LI, Bertrais S, Galan P, Arnault N, Potier de Couray G, Hercberg S. The use of computerised 24 h dietary recalls in the French SU.VI.MAX Study: number of recalls 
required. European Journal of Clinical Nutrition 2002; 56 659-65.

39 Saintot M, Astre C, Scali J, Gerber M. Within-subjects seasonal variation and determinants of inter-individual variations of plasma beta-carotene. International Journal for Vitamin and Nutrition Research 1995; 65: 169-74.

40 Relative validity and reproducibility of a diet history questionnaire in Spain. III. Biochemical markers. EPIC Group of Spain. European Prospective Investigation into Cancer and Nutrition. International Journal of Epidemiology 1997; 26: S110-7.

41 Kaaks R, Slimani N, Riboli E. Pilot phase studies on the accuracy of dietary intake measurements in the EPIC project: overall evaluation of results. European Prospective Investigation into Cancer and Nutrition. International Journal of Epidemiology 1997; 26: S26-36.

42 Homocysteine Lowering Trialists' Collaboration. Lowering blood homocysteine with folic acid based supplements: meta- analysis of randomised trials. Homocysteine Lowering Trialists' Collaboration. British Medical Journal 1998; 316 894-8.

43 Rimm EB, Ascherio A, Giovannucci E, Spiegelman D, Stampfer MJ, Willett WC. Vegetable, fruit, and cereal fiber intake and risk of coronary heart disease among men. Journal of the American Medical Association 1996; 275 447-51. 